\section{Lead in the environment}

A RECENT report of rising levels of lead in the blood of people living near a large British motorway interchange has highlighted the problem of lead pollution through exhaust emission. Lead can enter the environment in many ways. Food is generally considered to be the main source of lead intake; it has been estimated that each person takes in about 200-250 micrograms of lead in food daily. Lead is also released during lead smelting and other industrial processes but these are now subject to strict controls and although there is still pollution this affects only small areas.

In 1972 , about 90,000 tonnes of lead were added to petrol in the United Kingdom alone. Plans to reduce the level of lead in petrol to 0.45 grams per litre by 1975 have had to be shelved in view of the present oil crisis as producing high octane grades of petrol without the use of lead additives needs much more crude oil. At present the permitted maximum in the United Kingdom is 0.64 grams per litre.

The survey of blood lead levels of adults and children living around the Gravelly Hill interchange, 'Spaghetti Junction', was carried out by Birmingham City Council. Before the interchange opened in 1972 lead levels in residents' blood were on average 12.2 micrograms per 100 millilitres and last October had risen to an average of 16.6 micrograms. This January they showed a rise to an average level of 21.0 micrograms by the hospital analysis and 26.3 according to the Birmingham City Analyst. These discrepancies highlight one of the main problems in lead toxicology; the variability inherent in the methods used to measure blood lead levels.

The inference that is being drawn from the Birmingham report is that lead from traffic exhaust fumes is the cause of this rise in blood levels. The Birmingham Health Committee have expressed concern and are drawing the government's attention to the report. Although the average levels do not yet approach the accepted toxicity levels and are not above the upper limits for normality, a great deal of concern has been expressed over the past few years about the long term effects of exposure to subtoxic levels of lead especially in children. Also, there are bound to be individual higher than average levels.

The maximum acceptable level of lead in the blood of adult male workers exposed to lead for an eight hour day is considered to be 80 micrograms per 100 millilitres. For children the general concensus of opinion takes $36-40$ micrograms as the upper limits of nor- mality and considers 60 micrograms as cause for concern even though the child may not be showing any symptoms.

The whole question of the relation between the amount of lead in the atmosphere and its absorption into the body and link with blood lead levels is under intensive study at present. A study in 1972 by the Medical Research Council's Air Pollution Unit found that atmospheric levels of lead had risen in a busy London street from an average of 3.2 micrograms per cubic metre of air to 5.4 micrograms. A small survey of London taxi drivers during this time compared the blood lead levels of daytime with night-time drivers. Although

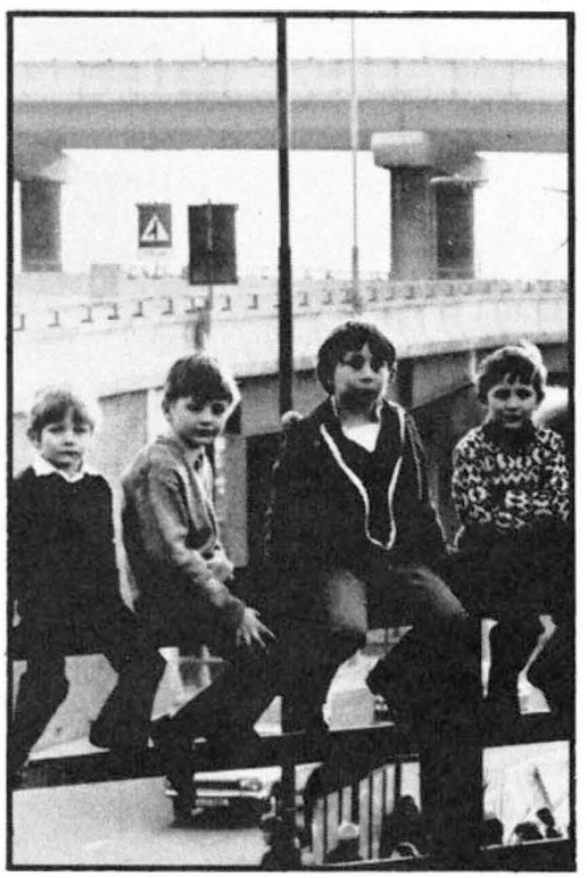

Spaghetti Junction: children at risk?

the daytime drivers were subjected to a higher level of exhaust pollution (monitored by the carbon monoxide effect on the blood) their blood lead levels were similar.

Much work on the size and aerodynamic properties of the lead particles given out in exhaust fumes is in progress. It has been estimated that about one-quarter of the lead content of petrol remains in the engine and the rest is given out in the exhaust as fine particles of lead compounds. Of this about half is thought to be deposited within a few hundred feet of the road but the finest particles may be carried considerable distances in the air. The fate of these particles in the lungs and how much is finally absorbed is also under study. The Atomic Energy Research Establishment at Harwell have just embarked on a study of the intake of roadiolabelled lead from exhaust fumes to try and throw light on this problem. Earlier work on artificial aerosol lead intake indicated an uptake of about $40-50 \%$, and more recent work in other laboratories suggests that about $15-20 \%$ of atmospheric lead is absorbed. Some workers, however, think that this figure is too low.

At present, there are many surveys measuring atmospheric and blood levels but it is often difficult to correlate the results of such different surveys. In a recent report, the Central Unit on Environmental Pollution drew attention to the difficulty of correlating results from different surveys. The report names lead as one of six pollutants which need monitoring on a wider scale than before. They recommend that a network of 20 sites be established in various areas to monitor trace elements by a standard technique. At present, a survey of traffic fume pollution is underway in five major British cities, coordinated by the government's Warren Spring Laboratory.

Additionally, the Worshipful Company of Pewterers celebrated its 500th anniversary by setting up a trust fund to provide an income of $£ 10,000$ a year for a research group at the Institute of Neurology, enquiring into the effects of heavy metals on the central nervous system. The first Pewterers Fellow, Dr Jeremy Barlow, has pointed out that, for the time being, the group doesn't quite know what it's looking for, but that there are certain facts, like the increased incidence of mental retardation in children in recent years, and about the amount of lead in the environment, which may or may not be related to each other.

The situation is further complicated by the fact that some individuals have a greater tolerance of lead in the body than others; one man may have taken in lead to the extent that his blood contains 1,000 micrograms per millilitre, and appear to be no worse off for the experience, whereas another individual may exhibit the clinical symptoms of lead poisoning at levels which are accepted as relatively safe. What's more, the symptoms are easily confused with the general symptoms of what is known as 'modern living' gut pains, insomnia, loss of appetite, and headaches, so that it's difficult to say that lead is specifically responsible whenever these symptoms occur.

Clearly a great deal of research has yet to be done before it is possible to say whether or not atmospheric pollution from car exhaust fumes is in any way responsible for higher levels of lead in the body, and that life, or health is endangered by the motor car. If we really want to be on the safe side in the meantime, it's possible to cut the lead content of petrol by producing high octane grades at great expense, or to stop using high-compression engines, which would mean that an awful lot of nice new cars would be made obsolete, at a stroke. 